\title{
Nonalcoholic fatty liver disease in patients investigated for elevated liver enzymes
}

\author{
Krikor Kichian $M D^{1}$, Ross Mclean $M^{2}{ }^{2}$, Leah M Gramlich $M^{1}{ }^{1}$, \\ Robert J Bailey $\mathrm{MD}^{1}$, Vincent G Bain $\mathrm{MD}^{1}$
}

\begin{abstract}
K Kichian, R Mclean, LM Gramlich, RJ Bailey, VG Bain. Nonalcoholic fatty liver disease in patients investigated for elevated liver enzymes. Can J Gastroenterol 2003;17(1):38-42.
\end{abstract}

Nonalcoholic fatty liver disease (NAFLD) is a common diagnosis among patients referred to gastroenterology and hepatology clinics for the evaluation of elevated liver enzymes. The diagnosis of NAFLD is supported by blood work to exclude other liver diseases, and by ultrasound evidence of fat in the liver in patients without a significant history of alcohol intake. The gold standard, however, is a liver biopsy to show the typical histological features of NAFLD, which are almost identical to those of alcohol-induced liver damage and can range from mild steatosis to cirrhosis. A variety of retrospective series have linked NAFLD to obesity, diabetes, hyperlipidemia, total parenteral nutrition, jejunoileal bypass surgery and certain medications. A subset of patients with NAFLD that had an initial presentation of elevated liver enzymes was studied. Two hundred and two patients were reviewed, of whom 49 met the inclusion criteria including a liver biopsy. Patients were excluded if insufficient data were available, if the patients had a significant history of ethanol intake or if they had other coexisting liver disease. These patients were seen between 1996 and 2000 in gastroenterology and hepatology clinics in two community hospitals and one regional liver transplant centre in Edmonton, Alberta. NAFLD was associated with a spectrum of changes in the liver ranging from mild steatosis to more significant steatosis with inflammation and fibrosis. Cases of NAFLD with steatosis and mixed inflammatory infiltration but lacking ballooning degeneration or fibrosis were prevalent in young (20 to 40 years of age) patients with no other significant medical history except for obesity. NAFLD with biopsies showing significant fibrosis and ballooning cell degeneration was associated with obesity, diabetes and older age. It was concluded that, in this predominantly outpatient setting, age over 40 years and diabetes at any age are risk factors for both nonalcoholic steatohepatitis and nonalcoholic steatohepatitis with cirrhosis. It is therefore recommended that patients with raised liver enzymes and suspected NAFLD be targeted for liver biopsy in their evaluation.

Key Words: Diabetes; Insulin resistance; Nonalcoholic fatty liver disease; Nonalcoholic steatohepatitis; Obesity

\section{Stéatose hépatique non alcoolique chez des patients examinés pour des taux élevés d'en- zymes hépatiques}

RÉSUMÉ : La stéatose hépatique non alcoolique (SHNA) se rencontre souvent chez les patients dirigés en gastro-entérologie et en hépatologie pour évaluation de taux élevés d'enzymes hépatiques. Le diagnostic de SHNA repose sur des examens sanguins pour écarter d'autres maladies possibles du foie et sur la présence de graisses dans le foie, décelée à l'échographie chez des patients n'ayant pas d'antécédents de consommation importante d'alcool. Il reste toutefois que l'examen de référence est la biopsie du foie, qui confirme les caractéristiques histologiques de la SHNA, presque identiques d'ailleurs à celles des maladies du foie causées par l'alcool; la gravité peut varier de stéatose légère à cirrhose. Dans plusieurs séries rétrospectives de cas, un lien a été établi entre la SHNA et l'obésité, le diabète, l'hyperlipidémie, la nutrition parentérale totale, les courts-circuits jéjunaux-iléaux et certains médicaments. Un sous-groupe de patients atteints de SHNA et présentant au départ des taux élevés d'enzymes hépatiques a fait l'objet d'étude. Les dossiers de 202 patients ont été revus, et 49 d'entre eux répondaient aux critères de sélection, dont une biopsie du foie. Ont été écartés les patients pour lesquels il n'y avait pas suffisamment de données, les patients qui avaient des antécédents de forte consommation d'alcool éthylique et ceux qui avaient d'autres hépatopathies concomitantes. Les patients en question ont été examinés entre 1996 et 2000 en gastro-entérologie et en hépatologie dans deux hôpitaux communautaires et un centre régional de transplantation du foie dans la région d'Edmonton. La SHNA a été associée à un large spectre de changements dans le foie, depuis la stéatose légère jusqu'à la stéatose importante accompagnée d'inflammation et de fibrose. Les cas de stéatose avec infiltration inflammatoire mixte mais sans dégénérescence hydropique ou fibrose étaient plus fréquents chez les jeunes (20 à 40 ans) patients, qui n'avaient pas d'autres antécédents médicaux notables que l'obésité. Par contre, la SHNA montrant à la biopsie une fibrose importante et une dégénérescence cellulaire hydropique était associée à l'obésité, au diabète et à un âge avancé. Nous sommes donc arrivés à la conclusion que, dans le présent groupe de patients en grande partie externes, un âge supérieur à 40 ans et le diabète, peu importe l'âge, constituaient des facteurs de risque tant de stéatose hépatique non alcoolique que de stéatose hépatique non alcoolique avec cirrhose. Il est donc recommandé qu'une biopsie du foie soit envisagée, dans le cadre de l'évaluation, chez les patients qui présentent des taux élevés d'enzymes hépatiques et chez qui une SHNA est présumée.
$\mathrm{N}$ onalcoholic fatty liver disease (NAFLD) is commonly diagnosed in outpatient hepatology and gastroenterology practices in North America (1). Patients with NAFLD have steatosis, which closely resembles alcoholic liver disease, but without a significant history of alcohol consump- tion. Nonalcoholic steatohepatitis (NASH) refers to NAFLD accompanied by evidence of fibrosis or inflammation in the liver biopsy in addition to steatosis (2). NAFLD without features of NASH is generally regarded as a benign disorder; however, it is estimated that up to $20 \%$ of patients

${ }^{1}$ Department of Medicine, Division of Gastroenterology, and ${ }^{2}$ Department of Pathology, University of Alberta, Edmonton, Alberta

Correspondence: Dr Vincent G Bain, Division of Gastroenterology, University of Alberta, 2E1.22 Walter MacKenzie Health Sciences Center;

8440-112 Street, Edmonton, Alberta T6G 2R7. Telephone 780-407-7238, fax 780-439-1922, e-mail vince.bain@ualberta.ca

Received for publication March 22, 2002. Accepted September 24, 2002 
with NASH progress to end-stage liver disease (3).

NAFLD is diagnosed by excluding a history of significant alcohol intake and by ruling out viral, autoimmune and other liver diseases. An echogenic liver on ultrasound suggesting fat infiltration further supports the diagnosis (4). Finally, liver biopsy showing steatosis with or without inflammation and fibrosis is considered the gold standard for diagnosis (5), but in practice it is often omitted because clinicians lack treatments that are proven to alter the natural history of this condition.

Treatment for NAFLD is aimed at correcting underlying contributing factors. This includes encouraging weight loss with diet and exercise in patients who are overweight (6), improving control of diabetes, treating hyperlipidemia and withdrawing any medications that may be contributing to NAFLD (7). The use of ursodeoxycholic acid, metformin and vitamin $\mathrm{E}$ is under investigation and they are yet to be proved to be effective in treating this disorder (8-10).

Most retrospective descriptive studies of NAFLD have focused on patients with biopsies typical for NASH. The initial series found that NASH was associated with female sex, obesity, type II diabetes, total parenteral nutrition, jejunoileal bypass, protein calorie malnutrition, hyperlipidemia and certain drugs $(2,3,11-13)$. More recently, investigators have described NASH in patients who were referred to outpatient clinics for an assessment of elevated liver enzymes. In contrast to the earlier series, these newer reports showed that NASH can occur in the absence of obesity and diabetes (14,15). Recently, Matteoni et al (16) described a heterogeneous cohort of patients with NAFLD, and showed a positive correlation between the severity of changes in the liver and clinical outcomes, including mortality.

We elected to further characterize patients with NAFLD by studying patients who were referred exclusively for raised liver enzymes. We took this approach to capture a more homogeneous study population and to further define this outpatient group, which continues to be a common clinical problem facing gastroenterologists and hepatologists.

\section{METHODS}

\section{Patients}

The search terms 'macrovesicular steatosis', 'steatohepatitis', 'fatty change' and 'fatty hepatitis' were used to locate liver biopsy reports from the computerized pathology registry of the regional health authority. The search spanned the time period between January 1996, when the computerized pathology registry was first set up, and April 2000. Ethical approval of the study was obtained from the regional health care authority. Two hundred and two patients were identified from the search and all their charts were reviewed.

The inclusion criterion was patients who had undergone biopsies exclusively as part of an assessment for elevated liver enzymes in the absence of significant alcohol history and with negative investigations for other causes of liver disease. All patients included in the study were screened for viral hepatitis (hepatitis B surface antigen, hepatitis $\mathrm{C}$ virus antibody), nuclear antibody, mitochondrial antibody, smooth muscle antibody, alpha 1 antitrypsin, copper and ceruloplasmin. Hemochromatosis was excluded by biopsy, by normal ferritin concentrations, and in patients with increased serum ferritin by liver biopsy and molecular genetic analysis for C282Y and H63D genes. Table 1 outlines the reasons for excluding 153 patients from the original list.

\section{Data collection}

After the inclusion and exclusion criteria were applied to the 202 patients identified from the registry, 49 were selected for a further review of their medical records. Data on age, sex, weight and height were collected. If weight and height data were not available in the chart, the consultation letters were used to look for history of obesity. Given the retrospective nature of the study, heights were not always available to calculate the body mass index (BMI) for all patients. Where BMI was available, a value greater than 26 was used to define patients who were overweight. The charts were also reviewed to identify diabetes, hypercholesterolemia, hypertriglyceridemia and the use of medications. Laboratory data collected at the time of liver biopsy were reviewed, and included serum alanine aminotransferase (ALT), aspartate aminotransferase (AST), alkaline phosphatase, ferritin, hemoglobin A1C, glucose, total cholesterol and tryglycerides. Finally, the radiology reports were examined for mention of fatty changes in the liver on ultrasound.

\section{Liver biopsies}

Biopsy specimens had been fixed in formalin and embedded in paraffin. Specimens had been stained with hematoxylin and eosin for morphological review and evaluation of inflammation. Masson's trichrome and reticulin stains were used to identify fibrosis. Most specimens were stained with Perls Prussian blue for iron storage. One hepatopathologist (RM), blinded to the patient's clinical and biochemical data, scored each biopsy according to the criteria set out by Brunt at al (17). A diagnosis of NASH was based on steatosis and the presence of ballooning cell degeneration or fibrosis in zone 3.

\section{Statistical analysis}

Data are given as percentages or means \pm SD. The twosided Student's $t$ test was used to compare quantitative variables, and proportions were compared by the $\chi^{2}$ method. A two-sided $\mathrm{P}<0.05$ was considered to indicate statistical significance in all analyses.

\section{RESULTS}

The age of the 49 patients selected from the original 202 patients was $46.4 \pm 13$ years (mean $\pm \mathrm{SE}$ ). As Table 2 shows, the patients were distributed across all age groups from 20 to more than 60 years, reflecting the heterogeneous nature of patients who are investigated for NAFLD. Table 2 also shows that the sex of the selected patients was equally divided between male and female. Finally, $63.2 \%$ of the 49 selected patients were seen at clinics in community-based hospitals compared with $36.7 \%$ seen at the regional liver 
TABLE 1

\begin{tabular}{|c|c|}
\hline Reason for exclusion & Number of patients \\
\hline History of ethanol intake & 24 \\
\hline Remote history of ethanol intake & 10 \\
\hline Presence of viral hepatitis & 28 \\
\hline Investigation for hepatic mass & 22 \\
\hline Use of known hepatotoxic drugs & 10 \\
\hline Cadaveric donor liver & 9 \\
\hline Prior liver transplantation & 5 \\
\hline Hemachromatosis & 2 \\
\hline Presence of obstructive liver disease & 12 \\
\hline Age less than 18 years & 3 \\
\hline Incomplete records & 25 \\
\hline
\end{tabular}

transplant centre.

Table 3 summarizes the liver biopsy findings. All patients had hepatic steatosis. None had microvesicular steatosis. The degree of steatosis was concordant with the extent of inflammation and fibrosis in 63\% of cases (that is, patients with mild steatosis had no or minimal fibrosis and those with severe steatosis had significant fibrosis). Ballooning hepatocytes were seen in $79.6 \%$ of the patients, of whom $92 \%$ had evidence of fibrosis in zone 3, qualifying them for a classification of NASH. Of patients with NASH, 16.7\% had cirrhosis. The presence of Mallory's hyaline bodies was reported in $36.7 \%$ of the patients and was associated with advanced fibrosis and inflammation. Finally, iron staining was assessed in 47 of the 49 patients and was positive in 16. There was no correlation between the presence or degree of iron staining and the stage of fibrosis or inflammation.

The 49 patients with NAFLD were categorized according to the type of changes in their liver biopsies (Table 4). The patients were divided into four groups: the steatosis only group consisted of patients with no or minimal evidence of fibrosis on biopsy; the NASH group were patients with fibrosis and presence of ballooning in zone 3; the $\mathrm{NASH}$ with cirrhosis group were those with cirrhosis attributed to NASH; and the total NASH group were patients with NASH with or without cirrhosis. In the steatosis only group, nine of the 13 patients had mild, two had moderate and two had severe steatosis. Of these patients, $69.2 \%$ were between the ages of 20 and 40 years. In contrast, patients with NASH or NASH with cirrhosis were considerably older, with only $26.6 \%$ and $0 \%$, respectively, below the age of 40 . The incidence of diabetes was also differed considerably between the groups. The steatosis only patients had no diabetes, while the patients with $\mathrm{NASH}$ or NASH with cirrhosis had a $36.1 \%$ incidence of diabetes. More importantly, in NASH patients with cirrhosis, the incidence of diabetes was 100\%. The majority of patients identified with steatosis only and NASH had above average weights, were described to have truncal fat, and had a high incidence of increased total cholesterol or triglyceride concentrations (data not shown).
TABLE 2

Characteristics of the $\mathbf{4 9}$ patients identified with
nonalcoholic fatty liver disease
\begin{tabular}{lc} 
Variable & Value \\
\hline Age (years) & \\
Mean \pm SE & $46.4 \pm 13.2$ \\
$<40(\%)$ & $17(34.7)$ \\
$41-50(\%)$ & $9(19.1)$ \\
$51-60(\%)$ & $15(30.6)$ \\
$>61(\%)$ & $8(16.3)$ \\
Male sex (\%) & $25(51.0)$ \\
Hospital distribution (\%) & \\
Royal Alexandra Hospital & $24(48.9)$ \\
Grey Nuns Hospital & $7(14.3)$ \\
University of Alberta Hospital & $18(36.7)$ \\
\hline
\end{tabular}

ALT was increased in the steatosis only group in $75 \%$ of patients compared with only $53.8 \%$ with increased AST. In contrast, both ALT (96.9\%) and AST (84.6\%) were increased in the NASH group. In addition, the mean rise of AST was significantly higher $(\mathrm{P}<0.05)$ in the NASH than in the steatosis only group, whereas the mean rise of ALT was almost equal in the two groups (Table 4). In contrast to the NASH group, patients with NASH and cirrhosis had a moderate rise in AST but no significant rise in ALT. The ratio of AST to ALT was compared in the four groups. As Table 4 shows, the ratio of AST to ALT was less then 1 in both the steatosis only and the NASH groups, and although this ratio tended to increase with advancing disease the difference did not reach statistical significance. Compared with both the steatosis only and the NASH groups, those with NASH and cirrhosis had a significantly higher ratio of AST to ALT at $2.34(\mathrm{P}<0.05)$. This group had only six patients but this result is in keeping with the increased AST to ALT ratio seen with other causes of cirrhosis. For the total NASH group, the ratio of AST to ALT was 1.0, trending to an increased AST to ALT ratio with advancing disease. However, the difference between the steatosis only and the total NASH groups did not reach statistical significance. Finally, ultrasound was useful in detecting fat in only $36.4 \%$ of patients with biopsies showing steatosis only compared with $79.2 \%$ of patients with NASH. The presence of fat was missed on ultrasound in $90 \%$ of patients with mild steatosis.

\section{DISCUSSION}

We have described a series of adult patients with liver biopsies compatible with NAFLD who were investigated in outpatient hepatology and gastroenterology clinics for increased liver enzymes. We found that NAFLD was present throughout a wide ranges of ages (20 to 64 years). Further, our data showed that NAFLD in young patients (20 to 40 years) was predominantly associated with being overweight and the absence of fibrosis on liver biopsies. In contrast, NAFLD in older patients (older than 40 years) was more likely to be associated with being overweight and with biopsies positive for inflammation or fibrosis. Finally, 


\begin{tabular}{|c|c|}
\hline Finding & Number of patients (\%) \\
\hline \multicolumn{2}{|c|}{ Macrovesicular steatosis } \\
\hline Mild & $23(46.9)$ \\
\hline Moderate & $18(36.7)$ \\
\hline Severe & $8(16.3)$ \\
\hline \multicolumn{2}{|c|}{ Evidence of zone 3 ballooning } \\
\hline Absent & $10(20.4)$ \\
\hline Present & $39(79.6)$ \\
\hline \multicolumn{2}{|c|}{ Necroinflammatory grade } \\
\hline 1 & $30(61.2)$ \\
\hline 2 & $17(34.7)$ \\
\hline 3 & $2(4.1)$ \\
\hline \multicolumn{2}{|c|}{ Mallory bodies } \\
\hline Absent & $31(63.3)$ \\
\hline Present & $18(36.7)$ \\
\hline \multicolumn{2}{|c|}{ Fibrosis stage } \\
\hline 0 & $12(24.5)$ \\
\hline 1 & $14(28.6)$ \\
\hline 2 & $9(18.4)$ \\
\hline 3 & $9(18.4)$ \\
\hline 4 & $5(10.2)$ \\
\hline \multicolumn{2}{|c|}{ Iron staining $(n=47)$} \\
\hline None & $31(66.0)$ \\
\hline Positive & $16(34.0)$ \\
\hline
\end{tabular}

${ }^{*}$ Biopsies scored according to the criteria set out by Brunt et al (17)

the presence of diabetes was associated with biopsies compatible with NASH regardless of age.

The patients described in this study share many characteristics with patients in previously reported series of NAFLD (13-16). Unlike in most studies, however, patients in our cohort had a broad age range, from 24 to 64 years. This age distribution most likely reflects the design of the study, where patients were recruited exclusively from outpatient clinics. This provided an opportunity to assess the degree of liver fibrosis in NAFLD with age. Our results show that the degree of liver fibrosis in NAFLD is closely correlated with advancing age. Despite this general trend, however, we identified several young patients (less than 35 years) who had typical features of NASH, showing that age is not the only determining factor for the development of NASH. This is supported by recent publications that have described NASH in children with obesity $(18,19)$.

Our results in this outpatient cohort are in agreement with previous reports, in that a significant rise in ALT alone is associated with steatosis only, while in patients with NASH a rise in both AST and ALT is consistently observed (15). However, we did not find in this small retrospective cohort that the ratio of AST to ALT could be used to predict the presence of liver fibrosis in individual patients. Ultrasound examination of the liver detected fat in only $37.5 \%$ of patients with biopsies limited to steatosis compared with $86.7 \%$ of patients with fat plus fibrosis or inflammation. The patients who were missed on ultrasound had only mild to moderate steatosis. These results are in agreement with previous reports and show that an ultrasound examination has low sensitivity in the diagnosis of NAFLD (4). We examined the incidence of obesity and diabetes in our cohort in light of several series that disputed the high incidence of these disorders in NASH $(14,15)$. Over $90 \%$ of NAFLD patients in our series had a BMI greater than 26 or were clearly described as being overweight, and over $40 \%$ were obese (BMI greater than 30 ). The incidence of hyperlipidemia and hypercholesterolemia was also high (greater than $80 \%$ ), albeit only $50 \%$ of the patients were assessed in our series (data not shown). The incidence of diabetes correlated strongly $(100 \%$ in our series) with advanced liver disease. The incidence of diabetes was low $(23.3 \%)$ in patients with NASH without cirrhosis and was absent in patients with no fibrosis. Given the retrospective nature of the study, however, we cannot comment on whether glycemic control or noncompliance with diabetes treatment was associated with liver fibrosis. Our study supports an important role for diabetes in the progression of NAFLD to NASH and subsequently to cirrhosis.

The indications for recommending a liver biopsy for suspected NAFLD remains controversial, with most practitioners not recommending a biopsy in asymptomatic patients with mildly increased liver enzymes. The argument against biopsy is that the information provided would change little in deciding on a treatment plan for these patients. On the other hand, advocates of liver biopsy argue that patients at increased risk of progressing to end-stage liver failure can be identified (9). In the Edmonton area, only a minority of patients had a liver biopsy as part of their investigation for the diagnosis of NAFLD. Given the reluctance to perform a liver biopsy for the diagnosis of NAFLD, we acknowledge that the data collected in this study reflect a population of patients who may have been relatively resistant to conservative management of NAFLD. This is reflected in the high proportion of patients with NASH.

The various mechanisms responsible for the development of NAFLD and its progression to NASH were reviewed recently $(20,21)$. A key event in the initiation of hepatic lipogenesis in NAFLD appears to be insulin resistance as shown by investigators using the two-step hyperinsulinemic euglycemic clamp technique $(22,23)$. Our data, which show that diabetes is an important factor in the development of fibrosis in patients with NAFLD, are consistent with these studies, which described the unequivocal presence of insulin resistance in NAFLD, as well as with evidence by Marceau et al (24) of a correlation between the development of diabetes and more advanced liver fibrosis in patients with syndrome X. Most studies show that being overweight or obese is an important contributing factor to insulin resistance; however, other studies that have also described NASH in normal weight patients argue that other, as yet unidentified mechanisms including a possible genetic predisposition may be important in the development of insulin resistance as well. 
TABLE 4

Patient characteristics analyzed according to their histological findings

\begin{tabular}{|c|c|c|c|c|}
\hline Variable & $\begin{array}{c}\text { Steatosis only }(n=13) \\
(26.5 \%)\end{array}$ & $\begin{array}{c}\text { NASH }(n=30) \\
(61.2 \%)\end{array}$ & $\begin{array}{l}\text { NASH and cirrhosis }(n=6) \\
(12.2 \%)\end{array}$ & $\begin{array}{c}\text { Total NASH }(\mathrm{n}=36) \\
(73.4 \%)\end{array}$ \\
\hline \multicolumn{5}{|l|}{ Age (years) } \\
\hline Mean \pm SE & $37.1 \pm 10.0$ & $47.9 \pm 12.7^{\star}$ & $57.7 \pm 8.8^{\dagger}$ & $49.5 \pm 12.6^{\ddagger}$ \\
\hline $20-40(\%)$ & $9(69.2)$ & $8(26.6)^{\S}$ & $0(0)^{\S}$ & $8(22.2)^{\ddagger}$ \\
\hline $41-50(\%)$ & $2(15.4)$ & $6(20.0)$ & $3(50.0)$ & $9(25.0)$ \\
\hline $51-60(\%)$ & $2(15.4)$ & $11(36.7)$ & $0(0)$ & $11(30.6)$ \\
\hline$>60(\%)$ & $0(0)$ & $5(16.7)$ & $3(50.0)^{9}$ & $8(22.2)$ \\
\hline Male sex (\%) & $7(54)$ & $16(53.3)$ & $2(33.3)$ & $18(50)$ \\
\hline Diabetes (\%) & $0(0)$ & $7(23.3)^{\star \star}$ & $6(100)^{\star \star}$ & $13(36.1)^{\ddagger}$ \\
\hline Overweight (\%) & $8(90.0) n=9$ & $22(92.0) n=24$ & $6(100)$ & $28(93.3) n=30$ \\
\hline Obesity (\%) BMI >30 & $4(44.5) n=9$ & $10(41.7) n=24$ & $3(50)$ & $13(43.3) n=30$ \\
\hline Fat on ultrasound (\%) & $4(36.4) n=11$ & $18(79.2) n=23^{\dagger}$ & NA & NA \\
\hline AST $(\mathrm{U} / \mathrm{L})(\text { mean } \pm \mathrm{SD})^{\dagger \dagger}$ & $50.08 \pm 27.3$ & $78.1 \pm 36.6^{\ddagger \ddagger}$ & $65.4 \pm 26.3$ & $76.7 \pm 36.9^{\ddagger}$ \\
\hline $\mathrm{ALT}(\mathrm{U} / \mathrm{L})(\text { mean } \pm \mathrm{SD})^{\dagger \dagger}$ & $106.1 \pm 79.9$ & $108.2 \pm 61.6$ & $48.1 \pm 28.3^{\S \S}$ & $108.1 \pm 78.9$ \\
\hline AST:ALT $(\text { mean } \pm S D)^{\dagger \dagger}$ & $0.63 \pm 0.43$ & $0.75 \pm 0.34$ & $2.34 \pm .31$ กที & $1.0 \pm 1.21$ \\
\hline
\end{tabular}

${ }^{*} P<0.01$ versus steatosis only; ${ }^{t} P<0.001$ versus steatosis only; $¥ P<0.05$ versus steatosis only; $\S P=0.0086$ versus steatosis only; ${ }^{\top} P=0.0004$ versus steatosis only; ${ }^{* *} P<0.0001$ versus nonalcoholic fatty liver disease (NAFLD) and nonalcoholic steatohepatitis (NASH) with cirrhosis; ${ }^{+t}$ Means were calculated from data for patients with available values for both aspartate aminotransferase (AST) and alanine aminotransferase (ALT) ( $n=12$ for steatosis only; $n=24$ for NASH, and $n=5$ for NASH with cirrhosis); ${ }^{\ddagger} P<0.05$ versus steatosis only; $\$ \S P<0.05$ versus $N A S H ; \uparrow T P<0.05 N A S H$ versus each of the other three groups. BMI Body mass index; $N A$ Not applicable

\section{CONCLUSION}

We have described the demographics and characteristics of a cohort of patients with NAFLD who had liver biopsies as part of their investigation for increased liver enzymes. NAFLD was seen in all age groups and was associated with a spectrum of changes on biopsy. Our study suggests that liver biopsy should be considered in patients with suspected NAFLD who are over 40 years of age or diabetic at any age. We caution, however, that our cohort consisted only of those selected for biopsy and not all patients,

\section{REFERENCES}

1. Byron D, Minuk GY. Clinical hepatology: Profile of an urban, hospitalbased practice. Hepatology 1996;24:813-5.

2. Ludwig Viggiano TR, McGill DB, Oh BJ. Nonalcoholic steatohepatitis: Mayo Clinic experiences with a hitherto unnamed disease. Mayo Clin Proc 1980;5:43-8.

3. Lee RG. Nonalcoholic steatohepatitis: A study of 49 patients. Hum Pathol 1989;20:594-8

4. Saveyuttu SH, Joseph AE, Maxwell JD. Ultrasound scanning in the detection of hepatic fibrosis and steatosis. BMJ (Clin Res Ed) 1986;292:13-5.

5. Brunt EM. Nonalcoholic steatohepatitis: Definition and pathology. Semin Liver Dis 2001;21:3-16.

6. Drenck EJ, Simmons F, Murphy JF. Effect on hepatic morphology of treatment of obesity by fasting, reducing diets and small-bowel bypass. $\mathrm{N}$ Engl J Med 1970;282:829-34.

7. James OFW, Day CP. Non-alcoholic steatohepatitis (NASH): A disease of emerging identity and importance. J Hepatol 1998;29:495-501.

8. Laurn J, Lindor KD, Crippin JS, et al. Ursodeoxycholic acid or clofibrate in the treatment of non-alcohol-induced steatohepatitis: A pilot study. Hepatology 1996;23:1464-7.

9. Coyl WJ, Delaney N, Yoshihashi A, Lawson P. Metformin treatment in patients with nonalcoholic steatohepatitis normalizes LFTs and improves histology. Gastroenterology 1999;116:A1198.

10. Lavine JE. Vitamin E treatment of nonalcoholic steatohepatitis in children: A pilot study. J Pediatr 2000;136:734-8.

11. Sheth SG, Gordon FD, Chopra S. Nonalcoholic steatohepatitis. Ann Intern Med 1997;126:137-45.

12. Wanless IR, Lentz JS. Fatty liver hepatitis (steatohepatitis) and obesity: An autopsy study with analysis of risk factors. Hepatology 1990;12:1106-10.

13. Powell EE, Cooksley WG, Hanson R, Searls J, Halliday JW, Powell LW. The natural history of nonalcoholic steatohepatitis: A which leaves open the possibility that there are other risk factors that were not identified. This study shows the need for prospective evaluations of patients with NAFLD to further characterize clinical factors and serological markers that may be used to identify patients with NAFLD with advanced liver damage.

ACKNOWLEDGEMENTS: We are grateful to Drs W Wong, M Ma, K Gutfreund, D Sadowski, CM Switzer, DN Todoruk and JP Ferguson for allowing us to review their patients.

follow-up study of forty-two patients for up to 21 years. Hepatology 1990;11:74-80.

14. Bacon BR, Farahvah MJ, Janney CG, Neuschwander-Terti BA. Nonalcoholic steatohepatitis: An expanded clinical entity. Gastroenterology 1994;107:1103-9.

15. Teli MR, James OFW, Burt AD, Banner MK, Burt CP. The natural history of nonalcoholic fatty liver: A follow-up study. Hepatology 1995;22:1714-9.

16. Matteoni CA, Younossi ZM, Gramlich T, Boparai N, Liu YC, McCullough AJ. Nonalcoholic fatty liver disease: A spectrum of clinical and pathological severity. Gastroenterology 1999;116:1413-9.

17. Brunt EM, Janney CG, Di Bisceglie AM, Neuschwander Tetri BA, Bacon BR. Nonalcoholic steatohepatitis: A proposal for grading and staging the histological lesions. Am J Gastroenterol 1999;94:2467-74

18. Manton ND, Lipsett J, Moore DJ, Davidson GP, Bourne AJ, Couper RT. Non-alcoholic steatohepatitis in children and adolescents. Med J Aust 2000;173:476-9.

19. Kinugasa A, Tsunamoto K, Furukawa N, Sawada T, Kusunoki T, Shimada N. Fatty liver and its fibrous changes found in simple obesity of children. J Pediatr Gastroenterol Nutr 1984;3:408-14.

20. Neuschwander-Tetri BA. Nonalcoholic steatohepatitis: An evolving diagnosis. Can J Gastroenterol 2000;14:321-6.

21. Tilg H, Diehl AM. Mechanisms of disease: Cytokines in alcoholic and nonalcoholic steatohepatitis. N Engl J Med 2000;343:1467-76.

22. Sanyal AJ, Campbell-Sargent C, Mirshahi F, et al. Nonalcoholic steatohepatitis: Association of insulin resistance and mitochondria abnormalities. Gastroenterology 2001;120:1183-92.

23. Marchesini G, Brizi M, Bianchi G, et al. Nonalcoholic fatty liver disease. A feature of metabolic syndrome. Diabetes 2001;50:1844-50.

24. Marceau P, Biron S, Hould F, et al. Liver pathology and the metabolic syndrome X in severe obesity. J Clin Endocrinol Metab 1999;84:1513-7. 


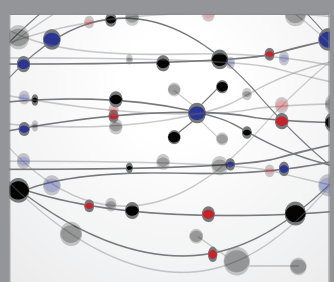

The Scientific World Journal
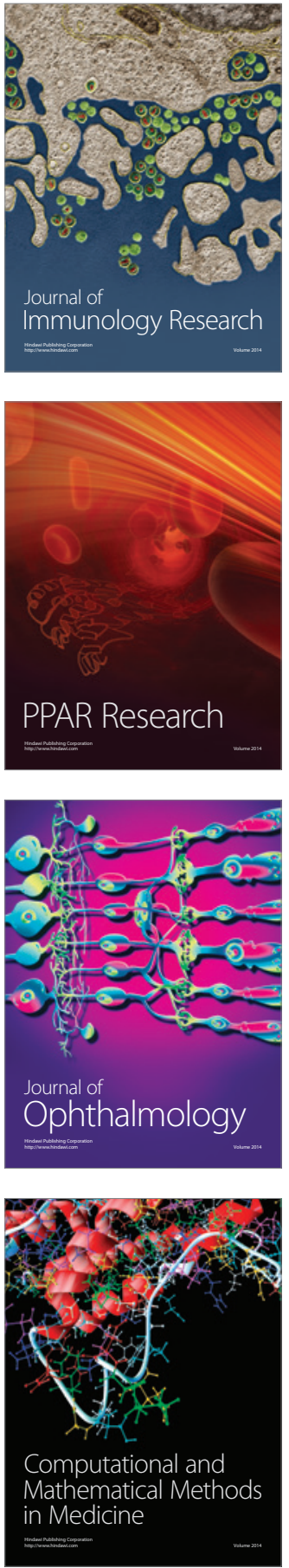

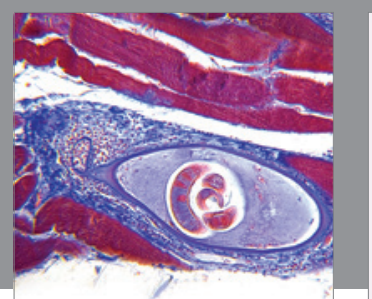

Gastroenterology Research and Practice

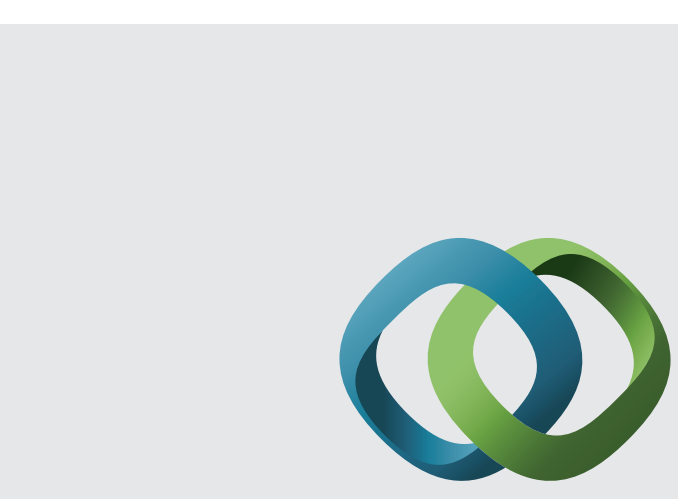

\section{Hindawi}

Submit your manuscripts at

http://www.hindawi.com
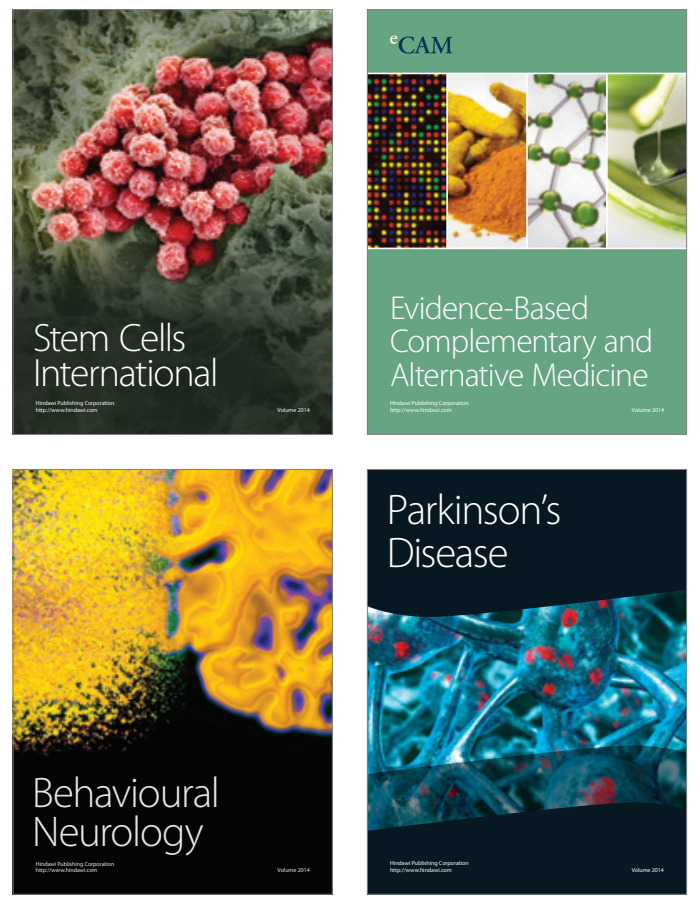
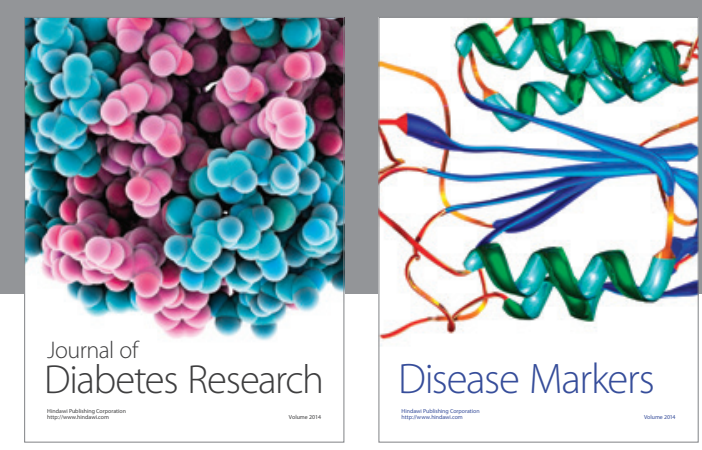

Disease Markers
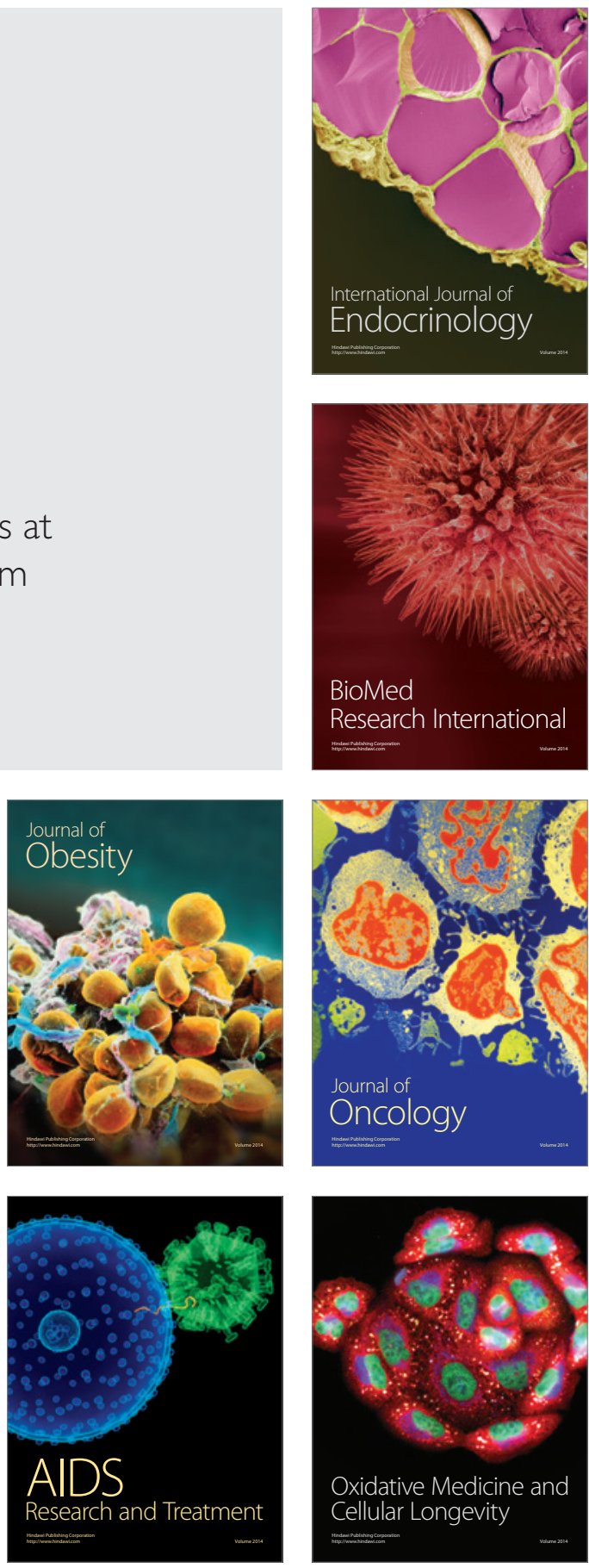